\title{
Evaluation of Wheat Bran as a Biosorbent for Potential Mitigation of Dye Pollution in Industrial Wastewaters
}

\author{
SUJATA DAS ${ }^{1}$, SHALINI SINGH ${ }^{1 *}$ and SHASHANK GARG ${ }^{1}$ \\ ${ }^{1}$ School of Bioengineering and Biosciences, Lovely Professional University, Punjab, India-144411. \\ ${ }^{*}$ Corresponding author E-mail: shalinisingh.iit@gmail.com \\ http://dx.doi.org/10.13005/ojc/350514
}

(Received: September 11, 2019; Accepted: October 12, 2019)

ABSTRACT

\begin{abstract}
Crystal violet (CV) is a basic dye that is extensively used for various industrial uses, ranging from, antimicrobial agent, paints, printing ink, biological stains, to textile dyes. Despite its many uses, it has been associated with environment pollution and toxicity, just like other chemical based industrial dyes, if not kept in check. In the current study, Wheat Bran, an agro-industrial waste reside, was tested for its adsorptive potential for removal/decrease of CV from industrial waste waters. Under optimized conditions of incubation $\left(\mathrm{pH} 8\right.$, temperature $30^{\circ} \mathrm{C}$, adsorbent concentration $10 \mathrm{~g} / \mathrm{L}$, time $180 \mathrm{~min}$ and adsorbate concentration $100 \mathrm{mg} / \mathrm{L}$ ), the adsorbent removed around $88 \%$ of $\mathrm{CV}$ from its aqueous solution, fitting appropriately adsorption model (Langmuir isotherm) with maximum adsorption capability $\left(\mathrm{q}_{\mathrm{m}}\right)$ value of $25.66 \mathrm{mg} / \mathrm{g}$, and following pseudo first-order kinetic model. Alkali treatment of adsorbent, though, showed around $4 \%$ increase in dye decolorization, but unmodified bran was preferred for further work to justify the need for cheap and environment friendly adsorbent to remediate industrial dye waste waters.
\end{abstract}

Keywords: Wheat Bran, Wheat Bran Adsorption, Crystal violet dye (CV), Isotherm, Biosorbents.

\section{INTRODUCTION}

Dyes are colored compounds, containing a chromophoric (credited for imparting color) and the auxochrome (credited for color intensity) group ${ }^{1}$ but chemical based conventional dyes are recalcitrant and long period persistent molecules that pose threat to environmental quality as well as life forms. Hence, efficient removal/neutralization of residual dyes before their release into the environment is of utmost concern for which different methods (physical, chemical and biological) are being evaluated for reducing dye pollution in water bodies.
Various physico-chemical treatment methods, like, electro-coagulation, flotation etc. are been employed but have shown limited success in degradation of water soluble, complex structured reactive textile dyes. Improved methods like, Membrane filtration and lon exchange (physical), Ozonation, Oxidation and Electrolysis (chemical) and microbiological (biological), alone or in different combinations, are providing some significant solutions to dye removal from wastewater. Still, the need for improved, more cost efficient and environment friendly methods to alleviate dye pollution, is ever increasing as many existing

This is an Open Access article licensed under a Creative Commons license: Attribution 4.0 International (CC- BY). Published by Oriental Scientific Publishing Company @ 2018

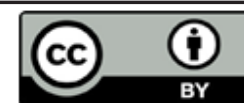


technologies are either too expensive or not-tooeffective to treat dye waste. Biosorption using low-cost agriculture-based residues like, wheat bran, rice husk, sugarcane dust, etc., is a cost effective, high performance remediation approach to bioremediation. These lignocellulosic matrices, with a wide variety of functional groups, efficiently bind to dyes through various mechanisms ${ }^{2}$. Consequently, the use of such biomaterials, both under modified and unmodified state, appreciably adsorb dyes from solutions. In the present study, wheat bran (WB) was evaluated as an adsorbent for the deduction/ removal of Crystal violet, a basic color, which finds its application in various industries like, biomedical, printing, textile etc.

\section{MATERIAL AND METHODS}

\section{Materials}

The chemicals, nutrient media, and reagents used in the current study were of analytical grade and purchased from HiMedia, Bangalore, India and Genei, Delhi, India. Pure Crystal violet $\left(\mathrm{C}_{25} \mathrm{~N}_{3} \mathrm{H}_{30} \mathrm{Cl}\right)$ was procured from Loba Chemi, Mumbai, India.

\section{Preprocessing of adsorbent}

Wheat bran was obtained from local market of Cantonment area, Jalandhar, Punjab, India. The lignocellulosic material, WB was washed with distilled water, to remove of all dirt particles, followed by drying to constant weight at $70^{\circ} \mathrm{C}$ for $8 \mathrm{~h}$ using a hot air oven. Dried bran was screened through mesh no. 30 $(0.6 \mathrm{~mm})$ and the sieved portion was transferred in sterile polybags/ziplock bags for further storage at room temperature in a cool and dry place ${ }^{3}$.

\section{Batch Adsorption Studies}

\section{Effect of pH on percent dye decolorization by test adsorbent}

The adsorption study was carried out in $100 \mathrm{ml}$ Erlenemyer flask with $20 \mathrm{ml}$ working volume of $100 \mathrm{mg} / \mathrm{L}$ of aqueous solution of CV. A weighed amount $(200 \mathrm{mg})$, of the biosorbent, at a concentration of $10 \mathrm{~g} / \mathrm{L}$, was added to the mixture. The conical flasks were kept under static condition, in the incubator by varying the initial $\mathrm{pH}(2,3,4,5$, $6,7,8,9,10,11,12$ ) of the aqueous dye solution at temperature of $30^{\circ} \mathrm{C}$ for $180 \mathrm{~min}$ to evaluate the influence of $\mathrm{pH}$ on adsorption capacity of wheat bran. The $\mathrm{pH}$ was adjusted by $0.1 \mathrm{M} \mathrm{NaOH}$ and $0.1 \mathrm{M} \mathrm{HCl}$ and measured by using a $\mathrm{pH}$ meter (VLab). After
$3 \mathrm{~h}$ (180 $\mathrm{min}), 2 \mathrm{ml}$ of samples were dispensed out in microcentrifuge tubes, centrifuged for $15 \mathrm{~min}$ at $5000 \mathrm{rpm}^{5}$. The supernatant was separated from pellet, and then residual concentration of test dye was spectrophotometrically determined in the collected supernatant, at $582 \mathrm{~nm}$ by using a UV/Vis double beamed spectrophotometer (Shimadzu-1800) ${ }^{4}$. The standard curve for crystal violet was plotted using different concentrations (10-130 mg/L) from its 1000 $\mathrm{mg} / \mathrm{L}$ stock solution, at $582 \mathrm{~nm}$ wavelength. The curve was used to calculate change in dye concentration after the adsorption on adsorbent 5 . The amount of dye (mg) adsorbed per unitWB (g), the adsorption capacity $\left(q_{e}\right)$ was determined as per mass balance (state of equilibrium, a condition beyond which no further adsorption can take place on the provided adsorbent) on the dye concentration and percent decolorization or dye removal efficiency were calculated according to the following Equations (1) ${ }^{6}$ and (2):

$\mathrm{q}_{\mathrm{e}}=\frac{\left(\mathrm{C}_{0}-\mathrm{C}_{\mathrm{e}}\right) \mathrm{v}}{\mathrm{w}}$

$\%$ decolorization $=\left[\mathrm{C}_{0}-\mathrm{C}_{\mathrm{e}} / \mathrm{C}_{0}\right] \times 100$

Where by, $C_{0}=$ Initial dye concentration (mg/L) and $\mathrm{C}_{\mathrm{e}}=$ Final dye concentration $(\mathrm{mg} / \mathrm{L}), \mathrm{V}$ is the sample volume (L) and W is the adsorbent's mass $(\mathrm{g})$.

Influence of Adsorbate concentration and Incubation period on percent dye decolorization The influence of adsorbate concentration $(10,20,30,40,50,60,70,80,90,100,110$, $130 \mathrm{mg} / \mathrm{L})$, adsorbate-adsorbent contact time $(30,60,90,120,150,180,210,240 \mathrm{~min})$ on adsorption equilibrium was investigated at an incubation temperature of $30^{\circ} \mathrm{C}$ at optimized $\mathrm{pH}$. The residual dye concentration was determined, spectrophotometrically at $582 \mathrm{~nm}$ wavelength, as already explained ${ }^{4}$. The dye adsorbed per unit WB and percent decolorization was calculated by using the above formulae respectively².

\section{Effect of adsorbent dosage on percent dye decolorization}

Variable concentration $(2,4,6,8,10$, $12,14 \mathrm{~g} / \mathrm{L}$ ) of adsorbent were suspended in optimized aqueous solution of adsorbate, at an optimized $\mathrm{pH}$ and incubation time, at $30^{\circ} \mathrm{C}$ and the remaining concentration of dye was determined spectrophotometrically for the calculation of dye per unit WB and decolorization percent on the basis of the above mentioned formulae ${ }^{2}$. 
Influence of Incubation Temperature on percent dye decolorization

The incubation temperature was varied $\left(25^{\circ}, 30^{\circ}, 35^{\circ}, 40^{\circ}, 45^{\circ}, 50^{\circ}, 55^{\circ}, 60^{\circ}, 65^{\circ}, 70^{\circ} \mathrm{C}\right)$ and its effect on equilibrium was evaluated by suspending WB in aqueous solution of $\mathrm{CV}$, maintained at optimum $\mathrm{pH}$ for optimized incubation time. The residual dye concentration and percent decolorization were estimated by using above mentioned formulae ${ }^{2}$.

\section{Effect of Chemical Modification of WB on percent decolorization}

$25 \mathrm{~g}$ of the bran and $250 \mathrm{~mL}$ of $0.4 \mathrm{~mol} / \mathrm{L}$ Citric Acid were mixed, and the mixture was dried for a duration of $2 \mathrm{~h}$ at $50^{\circ} \mathrm{C}$. The mixture was then centrifuged (4000 rpm), and the leftover solid-phase matter was further dried at $70^{\circ} \mathrm{C}$ for $6 \mathrm{~h}$ before it was grounded. Next, the material was esterified in presence of ethanol at $120^{\circ} \mathrm{C}$ for 3 hours. Further, the acid-functionalized Wheat Bran (AMWB) was washed repeatedly using $0.05 \mathrm{M}$ solution of $\mathrm{NaHCO}_{3}^{7,8}$, followed by washing with deionized water before being grounded and finally stored in dark coloured glass containers for further usage.

Similarly, $25 \mathrm{~g}$ of preprocessed bran was mixed with $5 \%$ solution of $\mathrm{NaOH}$ and sterilized at $121^{\circ} \mathrm{C}$ and 15 psi for 15 minute. Further, the bran was filtered to separate it from residual liquid, and then washed thoroughly with distilled water, until the $\mathrm{pH}$ of the filtered alkali solution was close to neutral. After drying at $70^{\circ} \mathrm{C}$ for $6 \mathrm{~h}$, the treated WB (ALMWB) was stored in dark colored bottles for its further usage ${ }^{9}$.

$200 \mathrm{mg}$ of adsorbent, each of acid-modified, alkali-modified and unmodified wheat bran was dispensed in $100 \mathrm{mg} / \mathrm{L}$ aqueous solution of test dye, incubated under optimized conditions of incubation time, temperature, $\mathrm{pH}$, adsorbent and adsorbate dosage 3 . Subsequently, the remaining dye concentration was found by spectrophotometrically for the determination of dye per unit WB and percent decolorization².

\section{Adsorption Isotherm studies}

Adsorption isotherms were using Langmuir and Freundlich ${ }^{10}$ isotherms by establishing a graphically represented relationship between the amount of dye adsorbed by absorbent $(10 \mathrm{~g} / \mathrm{L})$ and the residual adsorbate concentration in the given test medium at equilibrium, with different initial concentration (60-120 mg/L), at $30^{\circ} \mathrm{C}$ with initial $\mathrm{pH}$ of the medium set at 8 , for a duration of $180 \mathrm{~min}$ to show the distribution of adsorbate between the liquid phase and the solid phase.

The empirical model of adsorption is either given by Langmuir isotherm model, assuming that the adsorption can occur only at definite sites and at finite number of times. The non-linear expression of the model is ${ }^{6}$ :

$$
q_{e}=q_{m} k_{L} \frac{C_{e}}{1+k_{L} C_{e}}
$$

Where, $\mathrm{C}_{\mathrm{e}}$ denotes dye concentration ( $\mathrm{mg} / \mathrm{L}$ ) in the solution at equilibrium, $\mathrm{q}_{\mathrm{e}}$ denotes the adsorption capacity $(\mathrm{mg} / \mathrm{g}) ; \mathrm{q}_{\mathrm{m}}$ in $\mathrm{mg} / \mathrm{g}$, relates to maximum adsorption capacity as a constant, and $\mathrm{k}_{\mathrm{L}}$ in $\mathrm{L} / \mathrm{mg}$, is a constant in reference to energy of adsorption.

Or given by the Freundlich isotherm modeling system which describes the non-ideal and reversible adsorption, one of the most-earliest relationship known. Based on assumption, it can be applied to multilayer adsorption concerning surface energetic heterogeneity. The non-linear expression of this type of isotherm is given by ${ }^{11}$ :

$q_{e}=k_{f} C_{e}^{1 / n}$

Where $k_{f}$ is a constant relating to adsorption capacity and $n$ is a measure of intensity. The values of correlation coefficient, $\mathrm{R}^{2}$, normalized standard deviation have helped in comparison of isotherm equation with equilibrium constant to judge their applicability \& sustainability. The non-linear graph was plotted (Microsoft excel) for the determination of isotherm.

\section{Kinetic studies}

Under batch kinetic study, the adsorbentadsorbate was taken at predetermined time periods to measure the concentration of the solutions. The adsorption $\left(\mathrm{q}_{\mathrm{t}}\right)$ at time, $\mathrm{t}$ was determined by, Eq. 3. ${ }^{12}$ :

$$
q_{t}=\frac{\left(C_{0}-C_{t}\right) V}{W}
$$

Where, $\mathrm{C}_{0}$ and $\mathrm{C}_{\mathrm{t}}(\mathrm{mg} / \mathrm{L})$ are concentrations of the adsorbate in liquid phase at the initial and time, $t$, respectively. $V$ denotes the volume $(L)$ of the solution and $\mathrm{W}(\mathrm{g})$ is the adsorbent mass. By using pseudo-first and second order models the adsorption kinetics in the given case was investigated. 


\section{Pseudo First-order kinetic model}

The pseudo first order kinetic model is generally expressed ${ }^{13}$ :

$I_{n}\left(q_{e}-q_{t}\right)=\ln q_{e}-k_{1} t$

Where the amount of adsorbed dye at equilibrium is $\mathrm{q}_{\mathrm{e}}$, in $\mathrm{mg} / \mathrm{g}, \mathrm{q}_{\mathrm{t}}$, denotes the solute adsorbed/weight $(\mathrm{mg} / \mathrm{g})$ of the wheat bran at time $\mathrm{t}, \mathrm{k}$ depicted as $1 / \mathrm{h}$, is the rate constant of the pseudo first order sorption, a plot of $\ln \left(q_{e}-q_{t}\right)$ vs t gives a straight line with $k_{1}$ as slope and Inqe as an intercept.

\section{Pseudo second-order model}

The kinetic model of pseudo second order can be expressed as ${ }^{13}$ :

$$
\frac{t}{q_{t}}=\frac{1}{k_{2} q_{e}^{2}}+\frac{1}{q_{e}} t
$$

$1 / q_{e}$ and $1 / h$ is obtained as the slope \& intercept, respectively, of the linear plot of $t / q_{e}$ versus $t$.

\section{Statistical analysis of the data}

All the experiments have been conducted in triplicates. The mean values of the observed data have been presented and standard deviation was calculated.

\section{Spectroscopic analysis of active functional groups}

The structure and functional group information in reference to untreated, CV adsorbed untreated and chemically modified wheat bran was analyzed by Fourier Transfer Infrared (FTIR) spectroscopy using Model no 8400 S Shimadzu, in the range of $4000-500 \mathrm{~cm}^{-1}$ using potassium bromide $(\mathrm{KBr})$ disc containing $1 \%$ of finely ground treated and untreated wheat bran ${ }^{14}$.

\section{RESULT AND DISCUSSION}

\section{Batch Adsorption Studies}

The plot corresponding to the batch adsorption study (Fig. 1) reveals a gradual increase in removal of $\mathrm{CV}$ reaching to the maximum of $\mathrm{pH}$ 8 contradictory percentage of removal, $87.7 \%$. As
$\mathrm{pH}$ affects both the degree of ionization of the dye as well as the surface properties of the adsorbent, as hydrogen ions affect the surface charge of the adsorbents and the adsorbate species, the sorption is greatly affected by the variation of solution $\mathrm{pH}^{4}$. The point of zero charge $(\mathrm{pH} \mathrm{pzc})$ is also an important factor for the determination of the linear range of $\mathrm{pH}$ sensitivity indicating the type of surface-active centers and the ability of the surface to adsorb ${ }^{5}$. A decrease of $1 \%$ was seen at $\mathrm{pH} 9$, in comparison to percent decolorization at $\mathrm{pH}$ 8. Similar findings were reported in case of adsorption of $\mathrm{CV}$ on pearl millet, where maximum percentage of $\mathrm{CV}$ removal was observed at $\mathrm{pH} 11^{5}$. Another study reveals an increase in adsorptive capacity with increase $\mathrm{pH}$ from 3 to $9^{15}$. In another study, it has been shown that the interaction between Reactive Black 5 and chitosan is also dependent on $\mathrm{pH}$ of the solution, which affects surface charge on the sulphonate groups of the Reactive dyes and also that of chitosan which affects the degree of neutralization of amine groups $^{16}$ ( Elwakeel, 2009).

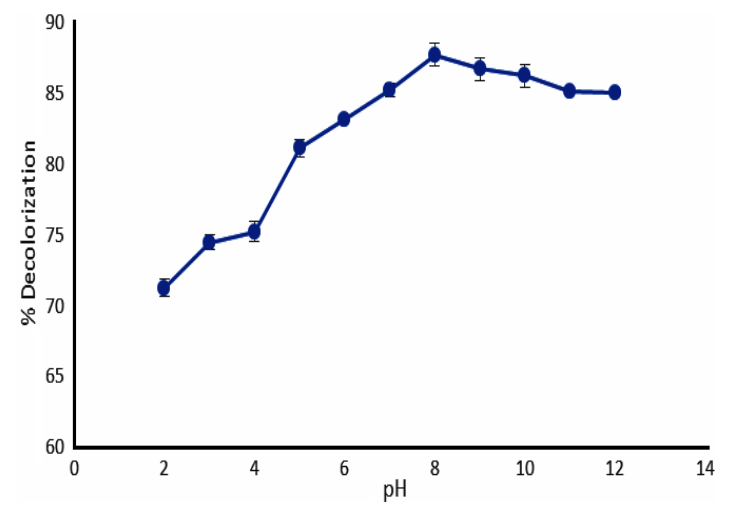

Fig. 1. Influence of $\mathrm{pH}$ on percent dye decolorization

The effect of initial adsorbate concentration (Table 1) was determined, where the highest percentage $(87.9 \%)$ of dye decolorization occurred at $100 \mathrm{mg} / \mathrm{L}$ adsorbate concentration after an incubation period of $180 \mathrm{~min}$ on $10 \mathrm{~g} / \mathrm{L}$ concentration of Wheat Bran at a temperature of $30^{\circ} \mathrm{C}$.

Table 1: Influence of initial dye concentration and incubation period on $\%$ removal of $\mathrm{CV}$

\begin{tabular}{|c|c|c|c|c|c|c|c|c|}
\hline \multirow[t]{2}{*}{ Dye (mg/ } & \multicolumn{8}{|c|}{ Time (min) } \\
\hline & 30 & 60 & 90 & 120 & 150 & 180 & 210 & 240 \\
\hline 60 & $55.96 \pm 0.7$ & $65.56 \pm 0.7$ & $78.95 \pm 0.4$ & $85.51 \pm 0.6$ & $87.12 \pm 0.4$ & $88.17 \pm 0.9$ & $88.73 \pm 0.3$ & $88.64 \pm 0.7$ \\
\hline 70 & $51.77 \pm 0.3$ & $58.80 \pm 0.2$ & $67.78 \pm 0.3$ & $78.30 \pm 0.3$ & $85.96 \pm 0.5$ & $88.08 \pm 0.6$ & $88.51 \pm 0.4$ & $88.57 \pm 0.6$ \\
\hline 80 & $46.05 \pm 0.1$ & $58.18 \pm 0.3$ & $66.09 \pm 0.9$ & $76.41 \pm 0.6$ & $84.20 \pm 0.2$ & $88.03 \pm 0.4$ & $88.05 \pm 0.9$ & $88.01 \pm 0.1$ \\
\hline 90 & $43.97 \pm 0.1$ & $54.78 \pm 0.1$ & $65.84 \pm 0.1$ & $74.67 \pm 0.1$ & $82.80 \pm 0.5$ & $87.98 \pm 0.6$ & $87.95 \pm 0.7$ & $87.92 \pm 0.4$ \\
\hline 100 & $38.39 \pm 0.7$ & $49.57 \pm 0.1$ & $58.87 \pm 0.9$ & $71.69 \pm 0.8$ & $81.99 \pm 0.2$ & $87.93 \pm 0.7$ & $87.85 \pm 0.3$ & $87.86 \pm 0.1$ \\
\hline 110 & $31.00 \pm 0.2$ & $43.64 \pm 0.2$ & $50.46 \pm 0.9$ & $68.24 \pm 0.4$ & $70.71 \pm 0.3$ & $77.65 \pm 0.2$ & $78.30 \pm 0.7$ & $78.93 \pm 0.2$ \\
\hline 120 & $24.00 \pm 0.3$ & $34.00 \pm 0.1$ & $45.45 \pm 0.5$ & $49.17 \pm 0.2$ & $52.76 \pm 0.4$ & $54.58 \pm 0.1$ & $56.24 \pm 0.2$ & $56.19 \pm 0.3$ \\
\hline
\end{tabular}

Incubation Conditions: $\mathrm{pH}: 8$; Adsorbent dose, gm/L:10; Temperature, ${ }^{\circ} \mathrm{C}: 30$ 
As indicated in Table 1, percent dye removal was higher under low concentration (30 mg/L) of dye, where as it decreases with increase in concentration of dye with a constant volume of adsorbent ( $10 \mathrm{~g} / \mathrm{L}$ ). This may be due availability of larger surface area at the beginning for the adsorption ${ }^{3}$. With increase in contact time, the percentage removal increase and it remains constant after $180 \mathrm{~min}$, showing reaching of equilibrium for different initial concentrations of $\mathrm{CV}$, with $100 \mathrm{mg} / \mathrm{L}$ concentration showing $88 \%$ dye removal. The adsorption and desorption occur simultaneously for which equilibrium reaches after an appropriate time, which may be attributed by the composition of the wheat bran ${ }^{17}$. A concentration of $2 \mathrm{gm} / \mathrm{L}$ for pearl millet, lead to a decrease in removal of CV from $80 \%$ to $71 \%$, dye concentration increased from $15-50 \mathrm{mg} / \mathrm{L}$, with equilibrium within $3 \mathrm{~h} 30 \mathrm{~min}^{5}$ (Selvapandiyan et al., 2015), as also similar to the current investigation where, $10 \%$ decrease in the CV removal percentage with increase in dye concentration from 100 to $110 \mathrm{mg} / \mathrm{L}$. Another study highlights equilibrium of $\mathrm{CV}$ adsorption on tamarind seed powder at around 50 min with $75.4 \%$ removal of the dye ${ }^{18}$ (Karthik et al., 2019).

The effect of adsorbent dosage (Fig. 2) was investigated at $30^{\circ} \mathrm{C}$ with the initial dye concentration of $100 \mathrm{mg} / \mathrm{L}$. A rapid surge in the dye removal with a rise in the dose of WB might be attributed to surface area availability with increasing concentration of the adsorbent.

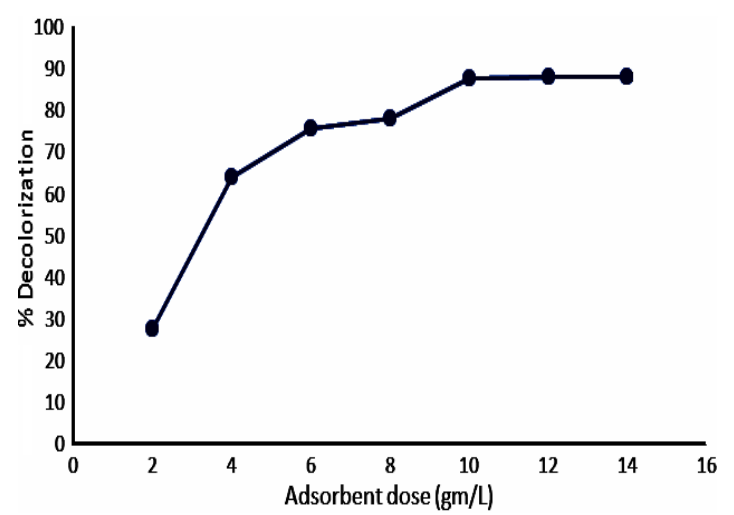

Fig. 2. Influence of adsorbent dose on percent decolorization of $\mathrm{CV}$

As the adsorbent dose increased from 2-4 mg/L, an abrupt increase in dye removal was observed from $28-64 \%$, followed by a gradual increase upto of $88 \%$ dye removal with adsorbent dose of $10 \mathrm{mg} / \mathrm{L}$. Beyond this, no significant change in the adsorption occurred. This might be because of over-crowding by the adsorbent particles which had led to the overlapping of the sites for adsorption ${ }^{19}$. Another study has revealed similar type of observations where, CV on Lysiloma latisiliquum seed powder, showed an increase in dye removal from $60-85 \%$ with an increasing adsorbent dose $(0.5-2.5 \mathrm{gm} / \mathrm{L})^{18}$. The findings indicate that percentage of $\mathrm{CV}$ adsorption on WB, determined by adsorption capacity, is within a specific range of initial concentration of $\mathrm{CV}$. The graph depicts that the maximum removal of dye was obtained in $10 \mathrm{~g} / \mathrm{L}$ dose of adsorbent showing the fluctuation to be a consequence of an increase in the no. of possible active sites and surface region of the adsorbent.

Under specific incubation conditions, temperature was found to influence dye adsorption as well, when $87.9 \% \mathrm{CV}$ removal by WB was seen at $30^{\circ} \mathrm{C}$ incubation temperature. Interestingly, the adsorptive ability was more or less similar even at higher temperatures of $35^{\circ} \mathrm{C}(87.12 \%$ dye removal) and $40^{\circ} \mathrm{C}$ ( $86 \%$ dye removal), with a sharp drop beyond $40^{\circ} \mathrm{C}$ incubation temperature (Figure 3 ).

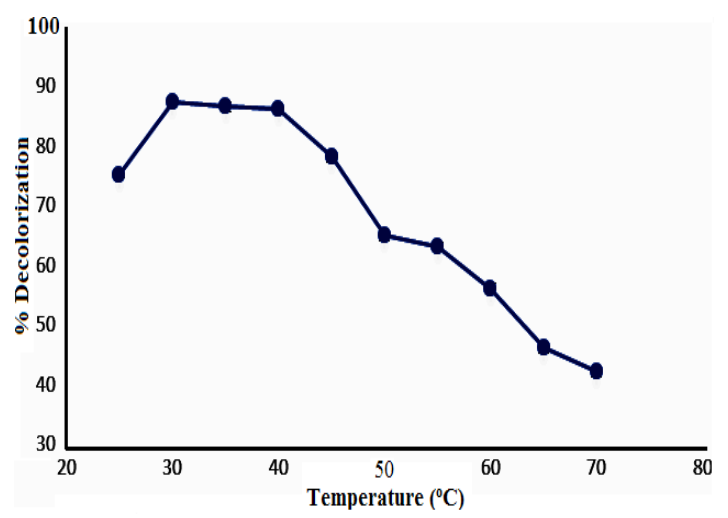

Fig. 3. Influence of IncubationTemperature on percent decolorization of $\mathrm{CV}$ using WB

The observation might be due to specific physical forces responsible for decrease in adsorption ${ }^{4}$. Adsorption studies of coomassie brilliant blue on wheat bran on the other hand, has shown an increase in the percent dye removal upto an temperature of $60^{\circ} \mathrm{C}$ beyond which, the absorptive efficiency decreased ${ }^{17}$.

Influence of acid and alkali modification of WB was studied to compare the effect of chemical modification of wheat bran with the unmodified sorbent (Fig. 4). Under static conditions, at a 
temperature of $30^{\circ} \mathrm{C}$, initial $\mathrm{pH}$ of 8 for a period of 180 min, alkali-modified wheat bran (ALMBW) yielded $92 \%$ of dye removal in comparison to unmodified WB $(88 \%)$. In contrast, acid-modified WB (AMBW) $(83 \%)$ did not perform better than unmodified WB. The carboxyl groups in acid modified WB is believed to be primarily responsible for the adsorption of the basic dyes ${ }^{20}$. Inferior performance of acid-modified bran, in comparison to both alkali-modified as well as unmodified bran, is inherently is expected to be contributed to proton, which most importantly influences at low $\mathrm{pH}$, and can consequently compete with cationic dyes for surface sites. Adsorption of methylene blue on papaya seeds showed that the adsorption was minimum at $\mathrm{pH} 3.0$, with increase in dye removal upto a pH of 4.0, after which, it remained constant ${ }^{21,2}$. In another study, adsorption by a chemically synthesized thiourea formaldehyde calcium alginate (TFCA) of Reactive black 5 was executed for checking the efficiency of adsorption and has shown that high adsorption capacity was shown under high acidic $\mathrm{pH}(\mathrm{pH} 1)$, where the most significant observation was observed after desorption studies, that is, the composite could be reused for adsorption for acidic dyes for several times by subjecting it to regeneration process by sodium hydroxide solution $(\mathrm{pH} 12)^{22}$. In another similar study with magnetic glycidyl methacrylate conjugated with a ligand diethylene triamine (MGMA-DETA) apart from an efficient removal of the dye AY99 by such chemically synthesized composite, under an optimized condition, the regeneration efficiency for each adsorption/desorption cycle, with $1.0 \mathrm{M} \mathrm{NaOH}$, of AY99 dye on the same had shown to be 88.2, 86.1 and $84.5 \%$ depicting a good efficiency minimally upto 4 cycles of their usage ${ }^{23}$.

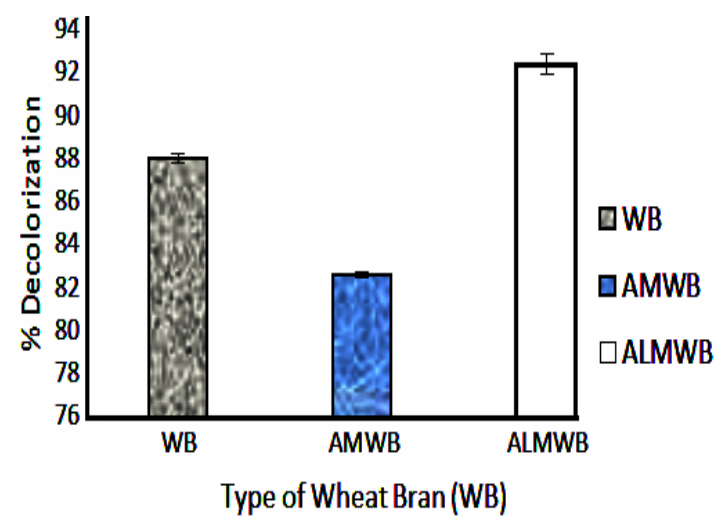

Fig. 4. Effect of Chemical Modification of WB on percent dye decolorization
The adsorption of CV on WB was studied as a function of different concentration $(\mathrm{mg} / \mathrm{L})$ of $\mathrm{CV}$, while keeping all other parameters, $\mathrm{pH}$ (8) and sorbent concentration $(10 \mathrm{~g} / \mathrm{L})$ constant and temperature $30^{\circ} \mathrm{C}$ for a period of 180 minutes. Fig. 5 reveals the relation between concentrations of the dye at equilibrium $\left(C_{e}\right)$ and their corresponding adsorption capacity $\left(\mathrm{q}_{\mathrm{e}}\right)$ respectively, showing at $100 \mathrm{mg} / \mathrm{L} \mathrm{CV}$, the adsorption capacity of WB has shown an increase till 180 min after which it remains constant showing that the equilibrium was reached. Such equilibrium study model depicts the dissemination of dye species between the solvent and the substrate based on assumptions related to homogeneity and heterogenous nature of adsorbents ${ }^{24}$. Fig. 5 depicts Langmuir and Freundlich isotherms for WB. Table 2 shows the corresponding values of the isotherm parameters, their correlation coefficients and related errors for each parameter. $\mathrm{R}^{2}$ value between 0 and 1 indicates favourable adsorption ${ }^{25}$. In Fig. 4 and Table 2, high correlation coefficient is deduced by fitting experimental data into Langmuir isotherm model $\left(R^{2}>0.9566\right)$ as in comparison to Freundlich isotherm model. This suggests that Langmuir models fits appropriately with the experimental data. The maximum adsorption capacity, as determined by Langmuir model was $25.66 \mathrm{mg} / \mathrm{g}$ and closely corresponds to the adsorption plateau, indicating that the given model is acceptable for adsorption. Besides, the system is following a monolayer adsorption mechanism.

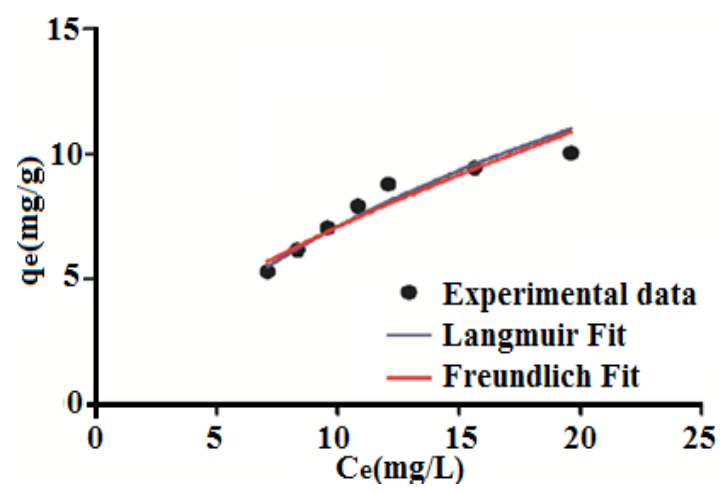

Fig. 5. Fit for Langmuir and Freundlich Isotherm

Table 2: Langmuir and Freundlich isotherm parameters obtained by non-linear fitting for WB, as an adsorbent

\begin{tabular}{lccc}
\hline \multicolumn{1}{c}{ Model/ Parameters } & & Value & S.E. \\
\hline Langmuir Isotherm Model & $\mathrm{q}_{\mathrm{m}}(\mathrm{mg} / \mathrm{g})$ & 25.66 & 6.248 \\
& $\mathrm{k}_{\mathrm{L}}$ & 0.03834 & 0.01287 \\
& $\mathrm{R}^{2}$ & 0.9566 & - \\
Freundlich Isotherm Model & $\mathrm{k}_{f}$ & 1.648 & 0.3346 \\
& $\mathrm{n}$ & 1.578 & 0.2071 \\
& $\mathrm{R}^{2}$ & 0.9207 & - \\
\hline
\end{tabular}


The adsorption kinetic study was important for the optimization dye adsorption conditions using given adsorbent. The two models used for adsorption kinetics of CV on WB were, pseudo first order and pseudo second order. Table 3 gives the calculated values of the constant and kinetic model parameters plotted at $30^{\circ} \mathrm{C} . \mathrm{q}_{\mathrm{e}}$ experimented value (93.29 $\mathrm{mg} / \mathrm{g}$ ) with $\mathrm{R}^{2}$ value 0.9578 more matching with pseudo first order kinetic model. Monolayer coverage capacities of WB for Reactive Blue 19, 195 and 145 dyes, in another study, were obtained as $117.6 \mathrm{mg} / \mathrm{g}, 119.1 \mathrm{mg} / \mathrm{g}$ and $196.1 \mathrm{mg} / \mathrm{g}$ at a temperature of $60^{\circ} \mathrm{C}$, respectively, with a regression coefficient $\left(R^{2}\right)$ for pseudo sec. order kinetic model higher than $0.99^{26}$, in contrast to that of the present study. A study revealed the characteristics of an efficient adsorbent, synthesized from left over sepia shells (SSBC, Sepia Shell Based Composite) having good ability for an efficient removal of both cationic (MB, Methylene Blue) and anionic (RB5, Reactive Black 5) dyes from their aqueous solution. Adsorption, as per Langmuir isotherm model, showed maximum adsorption capability reaching $254.05 \mathrm{mg} / \mathrm{g}$ and $269.18 \mathrm{mg} / \mathrm{g}$ for MB and RB5 respectively, with an additional ability of reusability after 4 repeated cycles with an adsorption capacity exceeding $86 \%{ }^{27}$.

Table 3: Constant values for adsorption kinetics for CV onto WB at a temperature of $30^{\circ} \mathrm{C}$

\begin{tabular}{ccc}
\hline Model & Kinetic Parameters & $\begin{array}{c}100 \mathrm{mg} / \mathrm{L} \text { concentration } \\
\text { of } \mathrm{CV}\end{array}$ \\
\hline Pseudo first order & & 93.29 \\
& $\mathrm{q}_{\mathrm{e}}(\mathrm{mg} / \mathrm{gm})$ & 0.01318 \\
& $\mathrm{k}_{1}$ & 0.9578 \\
Pseudo second order & $\mathrm{R}^{2}$ & 39.56 \\
& $\mathrm{q}_{\mathrm{e}}(\mathrm{mg} / \mathrm{g})$ & 0.0001751 \\
& $\mathrm{k}^{2}(/ \mathrm{min})$ & 0.9074 \\
\hline
\end{tabular}

Three major changes along with minor ones in the FT-IR spectrum of CV adsorbed WB could be observed by comparing it with that of unadsorbed WB spectrum. Fig. 6 and Fig. 7 reveal the reduction in amide $(-\mathrm{NH})$ group by the stretching band at $459 \mathrm{~cm}^{-1}$ and $522 \mathrm{~cm}^{-1}$ and stretching of hydroxyl $(-\mathrm{OH})$ group at $3308 \mathrm{~cm}^{-1}$ peak, this broad adsorption corresponds to carboxylic acids, alcohols, phenols as in lignin, pectin, and cellulose, indicating the presence of free $\mathrm{OH}$ (hydroxyl) groups on the surface of adsorbent used ${ }^{28,29}$. The changes in the absorption peaks of two spectrum, therefore, clearly indicates the adsorption of $\mathrm{CV}$ dye onto the surface of WB. Fig. 8 on comparison with Fig. 6 . Shows that there is change in the surface with the presence of ester bonds on acid treatment at $1730 \mathrm{~cm}^{-1}$, depicting the changes on the surface of the WB. Fig. 9 shows also shows changes on the surface of the WB after alkali treatment with medium and strong intensity, 1, 3, 5 substitutions. However, the regeneration capacity of such materials often poses a serious drawback, which may limit their practical application ${ }^{2}$. The adsorption process has thereby been reported as an efficient method for dye removal, ultimately producing treated effluent possessing the possibility of reusage.

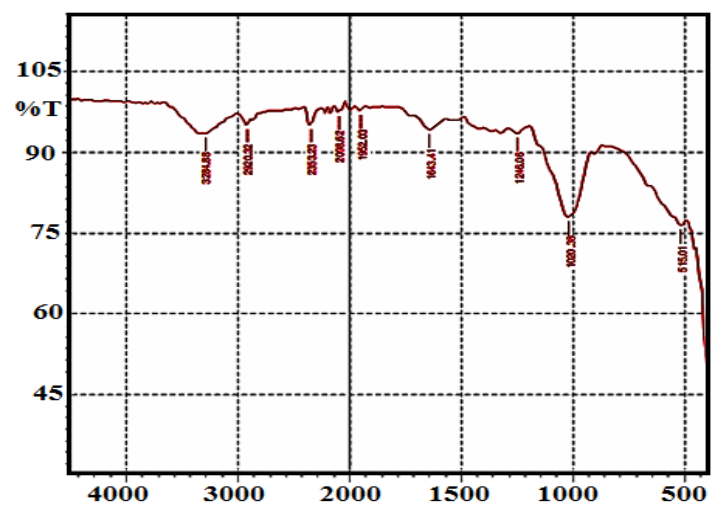

Fig. 6. FTIR of unadsorbed WB

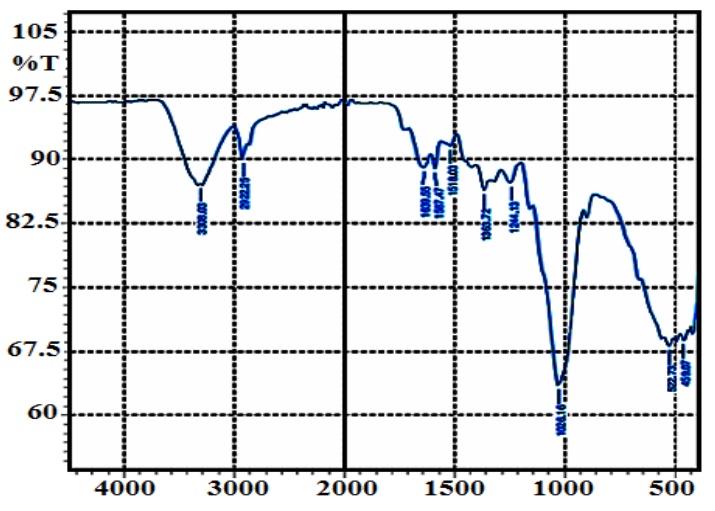

Fig. 7. FTIR of CV adsorbed WB

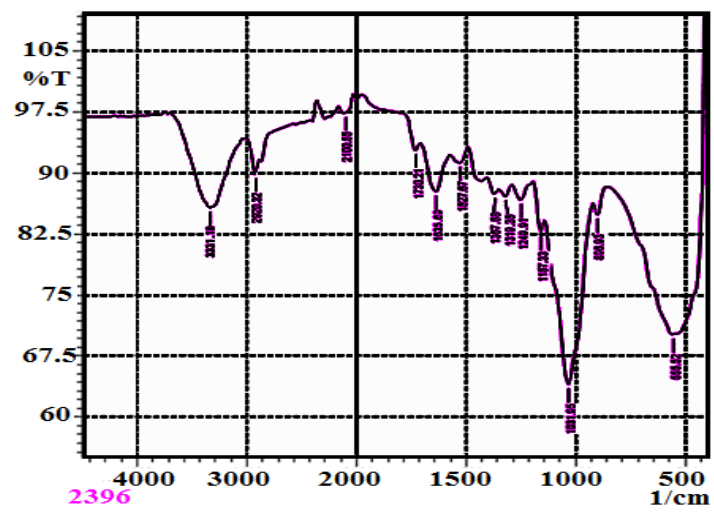

Fig. 8. FTIR of Acid Modified WB 


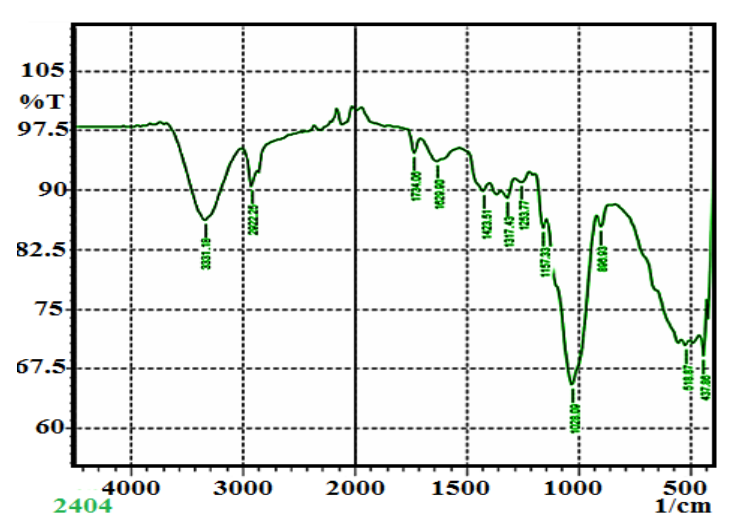

Fig. 9. FTIR of Alkali Modified WB

\section{CONCLUSION}

In summary, we have efficiently and successfully shown the use of wheat bran as adsorbent for reducing chemical dye pollution especially in reference to crystal violet, one of the most important chemical dyes used in industrial applications. Such effective, at the same time, natural and cheap lignocellulosic absorbents thus, can promisingly add to the search of environment friendly technologies for various industrial applications.

\section{ACKNOWLEDGEMENT}

The study was funded by Lovely Professional University, Punjab, India and the authors thank the Department of Microbiology, School of Bioengineering and Biosciences, Lovely Professional University for their generous help and support.

\section{Conflict of Interests}

The authors declare that there is no conflict of interests regarding the publication of this paper.

\section{REFERENCES}

1. Bharathi, K.S.; Ramesh, S.P.T.; Fixed-bed column studies on biosorption of crystal violet from aqueous solution by Citrullus lanatus rind and Cyperus rotundus, App. Water Sc., 2013, 3, 673-687.

2. Djilali, Y.; Elandaloussi, E.H.; Aziz, A.; Menorval, L.C.; Alkaline treatment of timber sawdust: A straightforward route toward effective low-cost adsorbent for the enhanced removal of basic dyes from the aqueous solution, J. Saudi Chem. Soc., 2012, 241-249.

3. Alzaydien, A.S.; Adsorption Behavior of Methyl Orange onto Wheat Bran: Role of Surface and pH, Orient. J. Chem., 2015, 31, 643-651.

4. Akazdam, S.; Chafi, M.; Yassine, W.; Gourich, B.; Removal of Acid Orange 7 Dye from Aqueous Solution Using the Exchange Resin Amberlite FPA-98 as an Efficient Adsorbent: Kinetics, Isotherms, and Thermodynamics Study, J. Mat. and Env. Sc., 2017, 8, 2993-3012.

5. Selvapandian, P.; Ananthakumar., K.; Cyril, A.; Biosorption of crystal violet from aqueous solution by pearl millet powder: Isotherm modelling and kinetic studies, J. App. Res. Wat. Was. Wat., 2015, 2, 143-149.

6. Zhu, B.; Fan, T.; Zhang, D.; Adsorption of Copper ions from aqueous solution by citric acid modified soyabean straw, J. Haz. Mat., 2008, 152, 300-308.
7. Hariharan, S.; Nambisan, P.; Optimization of lignin peroxidase, manganese peroxidase, and Lac production from Ganoderma lucidum under solid state fermentation of pineapple Leaf. Bio. Res. Tech., 2012, 8, 250-271.

8. $\quad$ Feng, Y.; Liu, Y.; Xue, L.; Sun, H.; Guo, Z.; Zhang, Y. and Yang, L.; Carboxylic acid functionalized sesame straw: a sustainable cost-effective bioadsorbent with superior dye adsorption capacity, Bio. Res. Tech., 2017, 238, 675-683.

9. Chowdhury, S.; Chakraborty, S.; Saha, P. D.; Response surface optimization of a dynamic dye adsorption process: a case study of crystal violet adsorption onto $\mathrm{NaOH}$-modified rice husk, Env. Sc. Pol. Res., 2013, 20, 16981705.

10. Bulut, Y.; Gozubenli, N. and Aydin, H.; Equilibrium and kinetics studies for adsorption of direct blue 71 from aqueous solution by wheat shells, J. of Haz. Mat., 2007, 144, 300-306.

11. Freundlich, H.M.F.; Over the adsorption in solution, J. Phy. Chem., 1906, 57, 385-471.

12. Zhou, Q.; Wang, X.; Liu, J.; Zhang, L.; Phosphorus removal from wastewater using nano-particulates of hydrated ferric oxide doped activated carbon fiber prepared by Sol-Gel method, Chem. Eng. J., 2012, 200, 619-626. 
13. Ho, Y.S.; Mackay, G.; The sorption of lead (II) ions on peat, W. Res. J., 1998, 33, 578-584.

14. Fisal, A.; Wan, D.W.M.A.; Ahmad, M.A.; Radzi, $R . ;$ The effects of acid leaching, on porosity and surface functional groups of cocoa (Theobroma cocoa)-shell based activated carbon, Chem Eng. Res. Des., 2013, 90, 1-11.

15. Madhavakrishnan, S.; Manickavasagam, K.; Vasanthakumar, R.; Rasappan, K.; Mohaviraj, R.; Pattabhi, S.; Crystal violet dye from aqueous solution using Rincus communis pericarp carbon as an adsorbent, E-J Chem., 2009, 1109-1116.

16. Elwakeel, K.Z., Removal of Reactive Black 5 from the aqueous solution using magnetic chitosan resins, J. Haz. Mat., 2009, 167, 383-392.

17. Ata, S.; Din, M.I.; Rasool, A.; Qasim, I.; Mohsin, Ul.; Equilibrium, thermodynamics and kinetics sorption studies for the removal of coomasie brilliant blue on wheat bran as a low-cost adsorbent, J. Ana. Met. Chem., 2012, 1-8.

18. Karthik, K.V.S.; Sudhkar, B.; Pranav, P.S.; Sridevi, $\mathrm{V}$.; Removal of crystal violet dye from aqueous solution through biosorption using Lysiloma latisilinquum seed powder: kinetics and isotherm; Int. J. Eng. Res. Tech., 2019, 8, 493-497.

19. Namasivayam, C.; Prabha, D.; Kumutha, M.; Removal of direct red and acid brilliant blue by adsorption on to banana pith, Bio Res. Tech., 1998, 64, 77-79.

20. Hashemian, S.; Dadfarnia, S.; Nateghi, M.R.; Gafoori, F.; Sorption of acid red 138 from aqueous solutions onto rice bran, Afr. J. Biotech., 2008, 7, 600-605.

21. Hameeda, B.H.; El-Khaiary, M.I.; Sorption kinetics and isotherm studies of a cationic dye using agricultural waste: broad bean peels, J. Haz. Mat., 2008, 154, 639-648.

22. El-Bindary, A.A.; Shoair, A.F.; Kiwaan, H.A.; Hawas, A.R.; Preparation, characterization and application of Synthesized Thiourea formaldehyde-calcium alginate in removing of Reactive Black-5, Can. J. Chem., 2018, 1-51.

23. Elwakeel, K.Z.; Ei-Bindary, A.A.; El-Sonabati, A.Z.; Hawas, A.R.; Adsorption of toxic acidic dye from aqueous solution onto diethylenetriamine fuctionalized magnetic glycidyl methacrylateN, N' methylenebisacrylamide, Roy. Soc. Chem. Adv., 2019, 1-46

24. Kumar, P.S.; Krithika, K.; Equilibrium and kinetic study of adsorption of nickel from aqueous solution onto bael tree leaf powder, J. Eng. Sc. Tech., 2009, 4, 351-363.

25. McKay, G.; Blair, H.S.; Gardner, J.R.; Adsorption of dyes on chitin. I. Equilibrium studies, J. App. Pol. Sc., 1982, 27, 3043-3057.

26. Cicek, F; Ozer, D.; Ozer, A.; Ozer, A; Low cost removal of reactive dyes using wheat bran, J. Haz. Mat., 2007, 146, 408-416.

27. Elgarahy, A.M.; Elwakeel, K.Z.; Elshowbaky, G.A.; Mohammad, S.H.; Untapped Sepia Shell-Based Composite for the sorption of cationic and anionic dyes, Wat. Air Soil Poll., 2019, 217-239.

28. Li, F.T.; Yang, H.; Zhao, Y.; Xu, R.; Novel modification of pectin for heavy metal adsorption, Ch. Chem. Let., 2007, 18, 325-328.

29. Liang, S.; Guo, X.; Feng, N.; Tian, Q.; Isotherms, kinetics and thermodynamic studies of adsorption of $\mathrm{Cu}^{2+}$ from aqueous solution by $\mathrm{Mg}^{2} / \mathrm{K}^{+}$type orange peel adsorbent, J. Haz. Mat., 2010, 174, 756-762. 